\title{
Comparison of AP-XPS and PLIF Measurements During CO Oxidation Over Pd Single Crystals
}

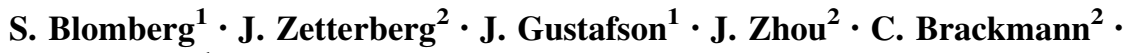 \\ E. Lundgren ${ }^{1}$
}

Published online: 4 January 2016

(c) The Author(s) 2016. This article is published with open access at Springerlink.com

\begin{abstract}
The interaction between the gas-phase molecules and a catalyst surface is crucial for the surface structure and are therefore important to consider when the active phase of a catalyst is studied. In this study we have used two different techniques to study the gas phase during $\mathrm{CO}$ oxidation over Pd single crystals. Gas-phase imaging by planar laser-induced fluorescence (PLIF) shows that a spherical boundary layer with a decreasing gradient of $\mathrm{CO}_{2}$ concentration out from the surface, is present close to the surface when the Pd crystal is highly active. Within this boundary layer the gas composition is completely different than that detected at the outlet of the chamber. The PLIF images of the gas-phase distribution are used to achieve a better understanding of the gas composition between the surface and the detector of a set-up for ambient pressure X-ray photoelectron spectroscopy (AP-XPS), a common technique for surface structure determination of model catalysts. The results show that also the gas-phase peaks present in the AP-XPS spectra truly represent the gas closest to the surface, which facilitates the interpretation of the AP-XPS spectra and thereby also the understanding of the mechanism behind the reaction process.
\end{abstract}

Keywords Ambient pressure X-ray photoelectron spectroscopy · Planar laser-induced fluorescence . $\operatorname{Pd}(100) \cdot \operatorname{Pd}(110) \cdot$ Gas-phase

S. Blomberg

sara.blomberg@sljus.lu.se

1 Division of Synchrotron Radiation Research, Lund University, Box 118, 22100 Lund, Sweden

2 Division of Combustion Physics, Lund University, Box 118, 22100 Lund, Sweden

\section{Introduction}

$\mathrm{CO}$ oxidation, where a $\mathrm{CO}$ molecule interacts with an oxygen molecule to form $\mathrm{CO}_{2}$, is one of many reactions that occur in an automotive catalyst to clean the exhaust gases from the toxic CO molecules. Due to its simplicity, the reaction is often used as a model reaction [1] and because its wide application the reaction has been studied in great detail for many decades [2]. The reaction process is well-known under ultra-high vacuum (UHV) conditions but less is known about the surface structure and reaction mechanism under more realistic operating conditions for the catalyst. More realistic conditions in turn involve higher pressure, which implies that the number of molecules interacting with the surface increases significantly. The gas molecules interacting with the catalyst surface are essential for the surface structure and a change in the gas composition close to the surface may result in a change of the surface composition $[3,4]$. It is therefore important to perform catalysis experiments in situ where knowledge of the gas molecules interacting with the surface can be achieved and used to understand the active surface structure of a catalyst in a better way [5].

There is a limited number of available techniques for probing the gas phase close to the surface of a model catalyst, and traditionally the gas composition has been analyzed using a mass spectrometer (MS) positioned at the reactor outlet. The MS data will therefore not reveal any direct information about the gas interacting with the surface and the actual connection between the MS signal and the gas distribution close to the surface is not clear. However, the development of traditional electron-based surface science techniques, enabling operation at higher pressures, has allowed for extraction of chemical information not only from the surface but also from the gas 
phase. Ambient pressure X-ray photoelectron spectroscopy (AP-XPS) [6, 7] is an example of a high-pressure set-up, common for catalysis studies, which is capable of monitoring surface reconstruction in situ as well as the gas phase close to the surface.

Oxidation of $\mathrm{CO}$ over transition metals is often mass transfer limited (MTL) by the minority reactants $[8,9]$ in the highly active regime of the catalyst. This means that the reaction is not kinetically controlled but, limited by the number of minority reactants that can penetrate a boundary layer of the product to reach the surface. The reaction is therefore completely controlled by diffusion of the reactants, which makes the gas-phase composition highly important for the catalytic process. Gas-phase studies using AP-XPS have been performed and reported in the literature [10-12], but very few have been performed for a highly active catalyst during $\mathrm{CO}$ oxidation [13-16]. As mentioned previously, the formation of a $\mathrm{CO}_{2}$ boundary layer changes the gas composition close to the sample surface, but how this is reflected in the AP-XPS gas-phase signal is not obvious. Planar laser-induced fluorescence (PLIF) has been shown to be capable of imaging the gas-phase distribution above an active catalyst surface with high spatial resolution [17-20]. The imaged gas-phase region is similar as the one probed by AP-XPS and can therefore contribute to an improved understanding of the AP-XPS spectra and, as a consequence, a better understanding of the details of the catalytic processes on the surface.

This contribution presents a comparison of the gas phase composition detected by AP-XPS and PLIF close to a highly active $\mathrm{Pd}$ catalyst surface exposed to a 1:1 mixture of $\mathrm{CO}$ and $\mathrm{O}_{2}$. By comparing the ratios of $\mathrm{CO}$ and $\mathrm{CO}_{2}$ for the two techniques, we show that AP-XPS probes the gas composition in the vicinity of the surface, and therefore provides a considerably better estimation of the gas composition as compared to an MS located at the outlet of the reactor.

\section{Experimental}

All experiments were performed in mixtures having a 1:1 ratio of $\mathrm{CO}$ and $\mathrm{O}_{2}$, but at different total pressures. In the AP-XPS experiment the total pressure was varied from 0.013 to 1.3 mbar [13]. The PLIF experiments performed for $\mathrm{CO}$ and $\mathrm{CO}_{2}$ detection were carried out at a total pressure of 106 and 150 mbar, respectively, where a pressure controller at the outlet was used to keep the pressure constant in the chamber. The partial pressures in the $\mathrm{CO}$ experiment were set to $26.5 \mathrm{mbar}\left(18 \mathrm{ml}_{\mathrm{n}} / \mathrm{min}\right)$ each for $\mathrm{CO}$ and $\mathrm{O}_{2}$, and to $53 \mathrm{mbar}\left(36 \mathrm{ml}_{\mathrm{n}} / \mathrm{min}\right)$ for $\mathrm{Ar}$ whereas 6 mbar $\left(4 \mathrm{ml}_{\mathrm{n}} / \mathrm{min}\right)$ each of $\mathrm{CO}$ and $\mathrm{O}_{2}$ and $138 \mathrm{mbar}(92 \mathrm{ml} / \mathrm{min})$ of $\mathrm{Ar}$ were used in the $\mathrm{CO}_{2}$ experiment. This results in a gas residence time in the chamber of $20 \mathrm{~s}$ for the $\mathrm{CO}$ experiment while in the $\mathrm{CO}_{2}$ experiment the gas residence time is only $2 \mathrm{~s}$. For the XPS experiment the inlet flow was controlled via a leak valve and the partial pressure of each gas was measured. No pressure controller was used and the inlet and outlet flow was constant throughout the whole experiment. In all experiments a standard BN heater [21, 22] was used to ramp the temperature of the crystal in order to start with an inactive crystal and then monitor the gas phase when the catalytic activity of the sample increases and reaches the highly active regime, in which the reaction is mass transfer limited.

\subsection{Ambient Pressure X-Ray Photoelectron Spectroscopy}

The AP-XPS measurements were carried out at beamline 9.3.2 at the ALS in Berkeley [10], CA, USA where differential pumping stages combined with electrostatic lenses enables reaction experiments in situ at pressures up to approximately 10 mbar. The sample was mounted on a special-made holder for catalysis experiments and a thermocouple was attached to the heating plate close to the single crystal. The set-up consists of two chambers between which the sample can be transferred without being exposed to air. This allows for sample preparation, such as sputtering, before transfer into the analysis chamber, where a hemispherical analyzer is attached. The gas pressures were controlled by individual leak valves. The only outlet from the analysis chamber is via the nozzle to the detector and in order to maintain the pressure at the surface to at least $98 \%$ of the inlet pressure at room temperature, the working distance between the sample and nozzle should be larger than twice the diameter of the aperture at the first pumping stage [10]. To achieve this for the present beamline set-up, the working distance was approximately $2 \mathrm{~mm}$, which is also the focus of the detector and implies that the number of detected electrons from the surface is optimized.

The $\mathrm{C}$ 1s spectra were measured with a photon energy of $435 \mathrm{eV}$ and the energy was calibrated to the Fermi level. The decomposition of the spectra was made using a Doniach and Sunjic [23] lineshape convoluted with a Gaussian lineshape and subtraction of a linear background.

\subsection{Planar Laser-Induced Fluorescence}

PLIF allows for species-specific detection in the gas phase with high sensitivity and two-dimensional imaging. The technique is commonly employed for combustion diagnostics, but less used in the field of catalysis [22, 24]. Here, we have used PLIF to visualize the gas-phase $\mathrm{CO}$ and $\mathrm{CO}_{2}$ above two different Pd single crystals. Two different laser 
systems and reactors were used for probing $\mathrm{CO}$ and $\mathrm{CO}_{2}$ respectively, but the layout of the experimental set-up was the same in both experiments and is shown in Fig. 1. In both set-ups an MS was attached to the gas outlet of the chamber for analysis of the overall gas composition. The $\operatorname{Pd}(100)$ crystal used for the $\mathrm{CO}_{2}$ experiment was the same as used in the AP-XPS experiments but when $\mathrm{CO}$ was probed a $\operatorname{Pd}(110)$ crystal, with the same size, was used. In these studies, thin lasersheets arranged perpendicular to the crystal surface probed $\mathrm{CO}$ and $\mathrm{CO}_{2}$ across the center of the crystals with wavelengths of $230 \mathrm{~nm}$ and $2.7 \mu \mathrm{m}$, respectively. The resulting fluorescence emission at $440-660 \mathrm{~nm}$ for $\mathrm{CO}$ and $4.26 \mu \mathrm{m}$ for $\mathrm{CO}_{2}$ was detected with a $\mathrm{CCD}$ camera and focal plane array detector, respectively, and images of an area of approximately $5 \times 16 \mathrm{~mm}^{2}$ of the specific gas distribution were obtained. The PLIF detection limit is at ppm levels and a spatial resolution better than 0.4 and $0.07 \mathrm{~mm}$ for the $\mathrm{CO}$ and $\mathrm{CO}_{2}$ measurements, respectively, were achieved in the presented measurements. The laser repetition rate was $10 \mathrm{~Hz}$, also representing the number of images taken every second. However, for noise reduction, the images shown in Fig. 4, are averaged over ten acquired images generating a timescale of 1 image/s. The analysis process for the PLIF images, which for instance includes temperature corrections and calibrations, is described in detail in [22].

\subsection{Sample Preparation}

Pd single crystals with surface orientation (100) and (110) were used as model catalysts. In the AP-XPS measurements the $\operatorname{Pd}(100)$ crystal was cleaned by sputtering and oxygen treatment in the preparation chamber. The crystal was then transferred into the analysis chamber without being exposed to air. The cleanness of the surface was then checked with AP-XPS before the reaction experiments were performed. In the PLIF experiments, the crystals were cleaned in the same way, with sputtering and oxygen treatment, but in this set-up there is no transfer system between the preparation chamber and the reactor, and the crystal was exposed to air before it was mounted in the reactor. To reduce contaminations on the surface the crystal temperature was ramped up and down in a $\mathrm{CO}$ and $\mathrm{O}_{2}$ environment before the reaction experiments were performed.

\section{Results}

In Fig. 2, the $\mathrm{C} 1 \mathrm{~s}$ spectra are shown, acquired during $\mathrm{CO}$ oxidation using a 1:1 ratio of $\mathrm{CO}$ and $\mathrm{O}_{2}$ at different total pressures [13] with a $\operatorname{Pd}(100)$ single crystal used as a model catalyst. The $\mathrm{O} 1 \mathrm{~s}$ and $\mathrm{Pd} 3 \mathrm{~d}_{5 / 2}$ core levels were also measured but are not shown here. Starting with the experiment at a total pressure of 1.3 mbar (Fig. 2a), the sample is inactive at low temperature and $\mathrm{CO}$ in the gas phase is clearly observed at approximately $290 \mathrm{eV}$. CO adsorbed in a bridge site on the $\operatorname{Pd}(100)$ surface is also detected at $286 \mathrm{eV}$ [25]. The temperature of the crystal is then stepwise increased and when a temperature of $340{ }^{\circ} \mathrm{C}$ is reached the sample is highly active and $\mathrm{CO}$ desorbs instantaneously from the surface simultaneously as the $\mathrm{CO}$ gas-phase peak disappears. In the spectrum measured at $340{ }^{\circ} \mathrm{C}$ a single peak, corresponding to $\mathrm{CO}_{2}$ in the gas phase, is observed, showing that the sample is highly active. When the temperature is increased further, no obvious increase in the $\mathrm{CO}_{2}$ gas-phase peak can be seen which shows that under these conditions, the reaction reaches its maximum conversion of $\mathrm{CO}$ to $\mathrm{CO}_{2}$ immediately after ignition. The conclusion is then that after ignition the reaction is not kinetically controlled but mass transfer limited by the $\mathrm{CO}$ diffusion. However, a highly
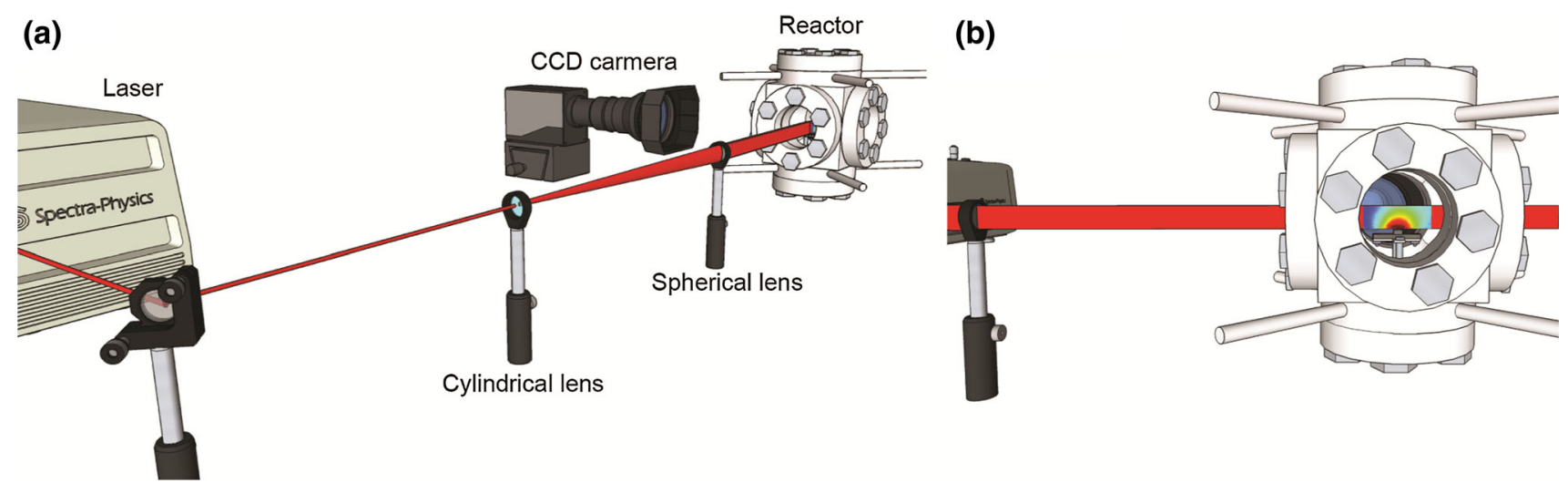

Fig. 1 An overview of the PLIF experimental set-up. a The laserbeam is shaped into a thin lasersheet by passing a cylindrical and spherical lens before it enters the reactor. The lasersheet can then probe the gas in two dimensions. $\mathbf{b}$ The fluorescence is detected by a CCD camera perpendicular to the lasersheet and a PLIF image of the gas distribution over the Pd crystal can be detected 
(a) Total pressure $1.3 \mathrm{mbar}$ $0.67 \mathrm{mbar}_{2} 0.67 \mathrm{mbar} \mathrm{CO}$

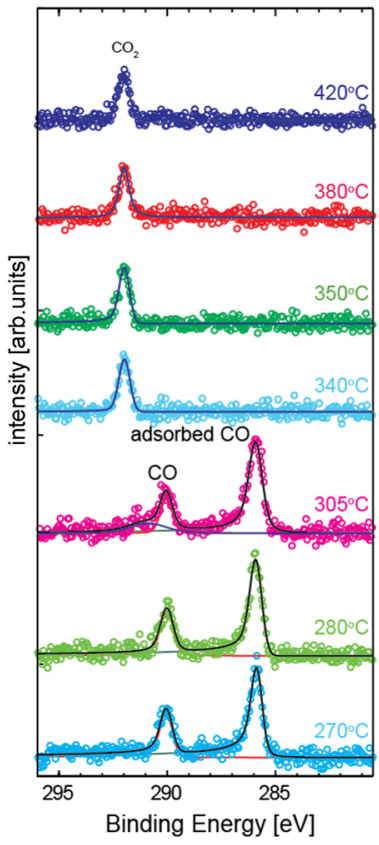

(b) Total pressure $0.67 \mathrm{mbar}$ $0.33 \mathrm{mbar}_{2} 0.33 \mathrm{mbar} \mathrm{CO}$

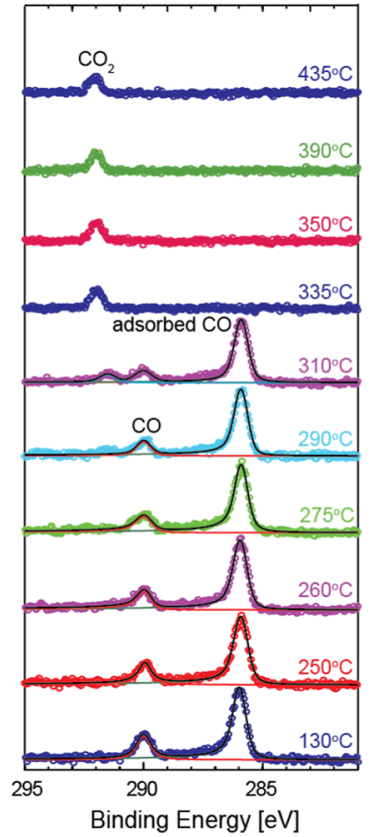

(c) Total pressure $0.13 \mathrm{mbar}$ $0.067 \mathrm{mbar}_{2} 0.067 \mathrm{mbar} \mathrm{CO}$

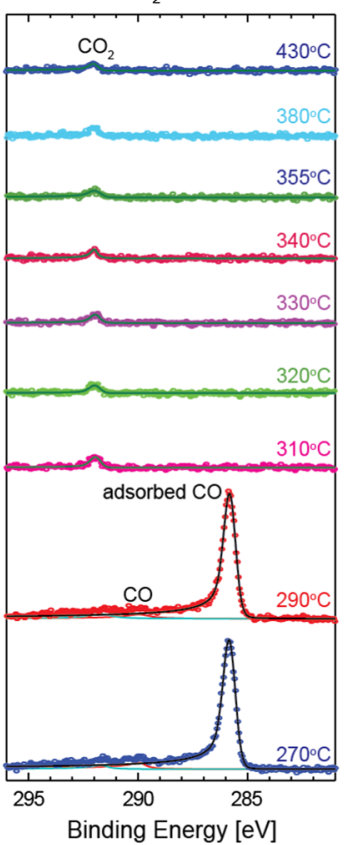

(d) Total pressure $0.013 \mathrm{mbar}$ $0.0067 \mathrm{mbar}_{2} 0.0067 \mathrm{mbar} \mathrm{CO}$

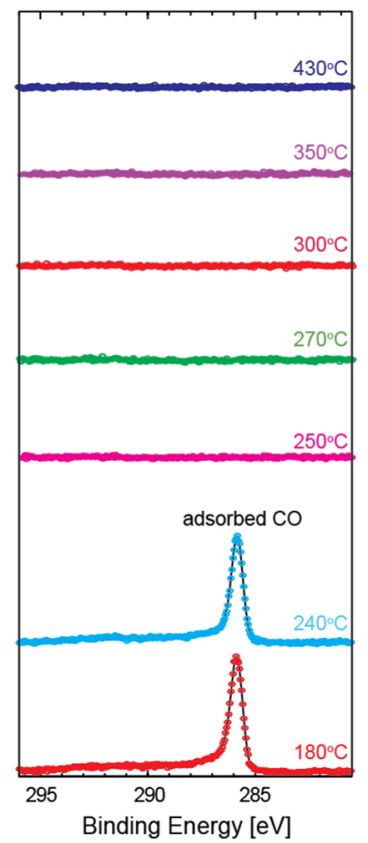

Fig. 2 AP-XPS C 1s spectra from CO oxidation using $\mathrm{Pd}(100)$ catalyst in 1:1 $\mathrm{CO}$ and $\mathrm{O}_{2}$ atmospheres at different total pressures a $1.3 \mathrm{mbar}$, b 0.67 mbar, c 0.13 mbar, d 0.013 mbar. $\mathrm{CO}_{2}$ and $\mathrm{CO}$ gas-phase peaks are observed as well as $\mathrm{CO}$ adsorbed on the surface

active sample producing a significant amount of $\mathrm{CO}_{2}$ should still have $\mathrm{CO}$ in the gas phase close to the surface to maintain its high activity. Surprisingly, no trace of CO can be is seen in the spectra after ignition. When the total pressure is reduced to 0.67 mbar, shown in Fig. $2 \mathrm{~b}$, a similar behavior can be observed. $\mathrm{CO}$ is adsorbed on the surface until the ignition temperature is reached and after ignition, which occurs at slightly lower temperature compared with the higher pressure (1.3 mbar), only gas-phase $\mathrm{CO}_{2}$ can be seen in the $\mathrm{C} 1 \mathrm{~s}$ spectra. Interestingly, at $310{ }^{\circ} \mathrm{C}$ both a $\mathrm{CO}_{2}$ and a $\mathrm{CO}$ gas-phase peak can be detected together with a peak originating from $\mathrm{CO}$ adsorbed on the surface, indicating that a complete MTL has not yet been reached, which in turn implies that only parts of the surface is fully active. We know from our previous studies [13] that chemisorbed oxygen starts to occupy the surface at this moment, but the exact nature of the surface is obviously still beyond our reach. To speculate, we could suggest that the surface consist of islands of atomic oxygen bordered by islands of $\mathrm{CO}$, and the $\mathrm{CO}_{2}$ production occurs at the border between the islands and/or at vacancies within the oxygen islands. Furthermore, it can also be seen that the $\mathrm{CO}_{2}$ peak is shifting towards higher energy as the surface goes from partly to fully active. The reason is the change in the surface work function $[26,27]$ as the CO desorbs fully from the surface and the oxygen fully adsorb on the surface. Decreasing the total pressure even further to 0.13 mbar (Fig. 2c) the ignition temperature is decreased to $310{ }^{\circ} \mathrm{C}$, but the CO-trend is still the same. It is also clear that the ratio between peaks of adsorbed $\mathrm{CO}$ and gas-phase $\mathrm{CO}$ is increasing with decreasing pressure, even though a similar CO coverage of the surface is expected for the different total pressures. This is simply because the number of molecules in the gas phase decreases when the pressure is reduced. The spread of the raw data (circles in Fig. 2) is also lower when the pressure is reduced, which results in more well-defined spectra. However, at an even lower total pressure of $0.013 \mathrm{mbar}$ (Fig. 2d), the partial pressures of $\mathrm{CO}$ and $\mathrm{CO}_{2}$ are too low to be detected and no gas-phase peaks in the $\mathrm{C} 1 \mathrm{~s}$ spectra can be observed. Still, the ignition temperature is concluded to be around $250{ }^{\circ} \mathrm{C}$, due to the absence of the peak corresponding to adsorbed $\mathrm{CO}$ at this temperature. In fact, the absence of a peak corresponding to $\mathrm{CO}$ adsorbed on the surface demonstrates a very low coverage suggesting that the reaction is extremely fast, and that all $\mathrm{CO}$ reaching the surface instantaneously is converted to $\mathrm{CO}_{2}$.

To investigate the changes in the gas phase in more detail the areas of the $\mathrm{CO}$ and $\mathrm{CO}_{2}$ gas-phase peaks are extracted from the $\mathrm{C} 1 \mathrm{~s}$ spectra and plotted in Fig. 3. The advantage of extracting the $\mathrm{CO}$ and $\mathrm{CO}_{2}$ peak areas from the same spectrum is that difficulties such as compensation for background and number-of-sweeps, are reduced. In addition, the cross sections for $\mathrm{CO}$ and $\mathrm{CO}_{2}$ in the gas phase are similar [28], making it possible to compare the integrated intensities of the peaks. In the plots, the peak 


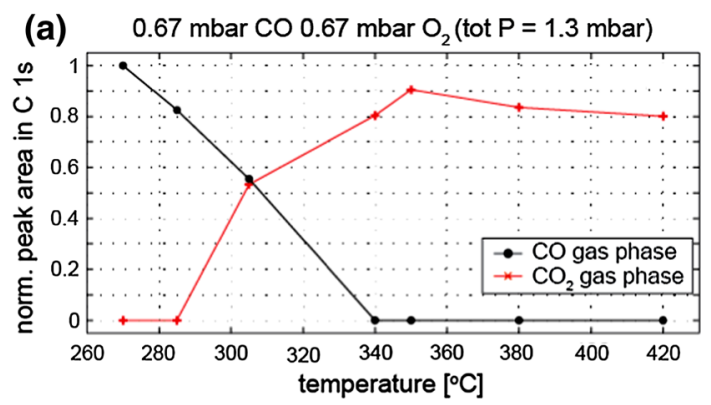

(b) $0.33 \mathrm{mbar} \mathrm{CO} 0.33 \mathrm{mbar}_{2}$ (tot $\mathrm{P}=0.67 \mathrm{mbar}$ )

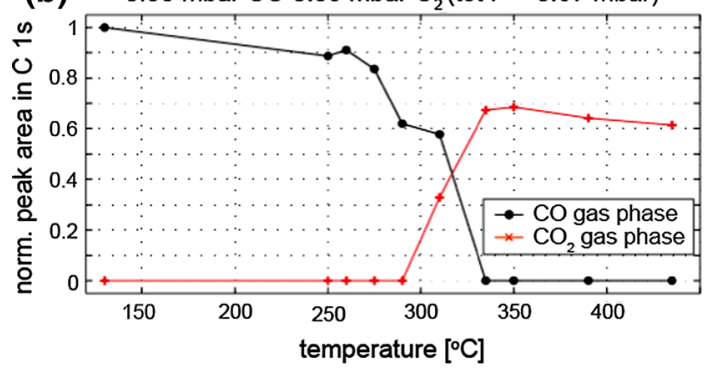

(c) $0.067 \mathrm{mbar} \mathrm{CO} 0.067 \mathrm{mbar} \mathrm{O}_{2}$ (tot $\mathrm{P}=0.13 \mathrm{mbar}$ )

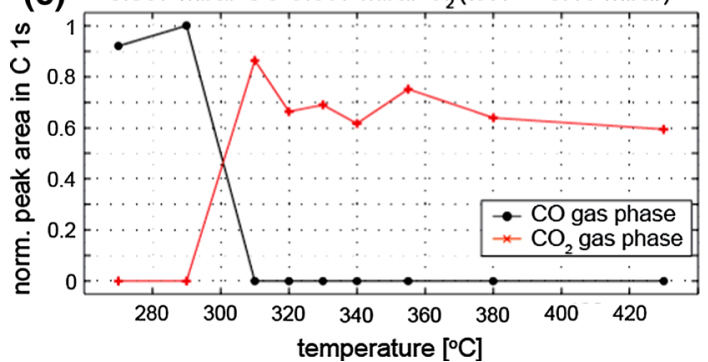

Fig. 3 Normalized $\mathrm{CO}$ and $\mathrm{CO}_{2}$ gas-phase peak areas, evaluated from the AP-XPS C 1s spectra, plotted versus catalyst temperature for different total pressures a 1.3 mbar, b 0.67 mbar, c 0.13 mbar. Lines have been inserted between the measurement points for guidance

areas are normalized to the area of the $\mathrm{CO}$ peak in the beginning of the experiment but similar results are achieved by plotting the ratios between the gas-phase peaks and the Pd substrate peak. The error of the data can be estimated to be $\pm 5 \%$, based on the statistical error between consecutive scans. Figure 3 a shows results for a total pressure of 1.3 mbar, where the area of the $\mathrm{CO}$ gasphase peak (black points) decreases when the temperature is increased while the $\mathrm{CO}_{2}$ peak is not detectable until after ignition. At ignition the $\mathrm{CO}$ peak decreases to zero and the $\mathrm{CO}_{2}$ peak area increases (red crosses) to an approximately constant level confirming that the MTL regime is reached. Figure $3 b$ and $c$ show the peak areas at the lower total pressures of 0.67 and 0.13 mbar. No obvious difference can be seen between the three plots, suggesting that the gas composition close to the surface is similar for all three total pressures. The absence of the $\mathrm{CO}$ gas-phase peak after ignition could be interpreted as no $\mathrm{CO}$ molecules are present in the gas phase close to the surface after ignition but instead immediately converted into $\mathrm{CO}_{2}$. However, for none of the three experiments in which the gas phase is detected, the $\mathrm{CO}_{2}$ peak area reaches the same peak area as the CO prior to ignition (it only reaches $60-80 \%$ of the $\mathrm{CO}$ peak). This would then suggest that $\mathrm{CO}$ is still present in the gas phase but below the detection limit of the AP-XPS set-up, however, the interpretation of the data is still not obvious. It is of particular interest to know how the gasphase peaks observed in the AP-XPS spectra are related to the actual gas composition close to the surface. In an attempt to answer this question we have investigated the composition of the gas-phase more thoroughly using PLIF.

PLIF images of $\mathrm{CO}$ and $\mathrm{CO}_{2}$ acquired at three different temperatures, respectively, during the temperature ramp, are shown in Fig. 4. The images represent the gas composition of an inactive sample (image I), at ignition (image II), and a highly active sample (image III). Due to the different ignition temperatures of the crystals $\left[365^{\circ} \mathrm{C}\right.$ for $\operatorname{Pd}(110)$ and $270{ }^{\circ} \mathrm{C}$ for the $\left.\mathrm{Pd}(100)\right]$ the temperature of the samples when the images were acquired are different for the $\mathrm{CO}$ and $\mathrm{CO}_{2}$ cases. Starting with images acquired at the lowest temperatures, the lack of $\mathrm{CO}_{2}$ PLIF signal and the homogenous partial pressure of $\mathrm{CO}$ clearly indicates that the samples are inactive at these temperatures (image I). When the ignition temperatures of the samples are reached, local changes in the gas composition close to the surface are observed (image II). Immediately after ignition, a spherically shaped region with increased $\mathrm{CO}_{2}$ concentration is formed around the surface (image III) which stays unchanged even if the temperature is increased further. This is a visualization of the boundary layer of the $\mathrm{CO}_{2}$ that hinders $\mathrm{CO}$ from reaching the surface in the MTL regime, consistent with the reduced $\mathrm{CO}$ signal detected in the corresponding region. The images show that after the boundary layer is formed, the changes in the gas composition close to the surface are small, indicating steady state conditions in the gas phase. It is also clear that the gasphase evolution during the reaction is comparable for both crystals and that the surface structure does not affect the gas phase significantly, which is in agreement with the results reported by Toyoshima et al. [14, 15]. They also report a lower ignition temperature for $\operatorname{Pd}(110)$ compared to the $\operatorname{Pd}(100)$, which is not observed in the PLIF studies, possibly because different chambers with different gas flow properties were used for the two experiments. The partial pressures of $\mathrm{CO}$ and $\mathrm{O}_{2}$ are also higher $(26.5 \mathrm{mbar}$ ) in the experiment where the $\operatorname{Pd}(110)$ was used compared to the partial pressures used when the $\operatorname{Pd}(100)$ crystal was investigated (6 mbar). This may also contribute to a higher ignition temperature for the $\operatorname{Pd}(110)$ compared with the $\operatorname{Pd}(100)$ crystal.

Figure 5a shows MS data recorded during $\mathrm{CO}$ oxidation over $\operatorname{Pd}(110)$. When the sample temperature reaches 

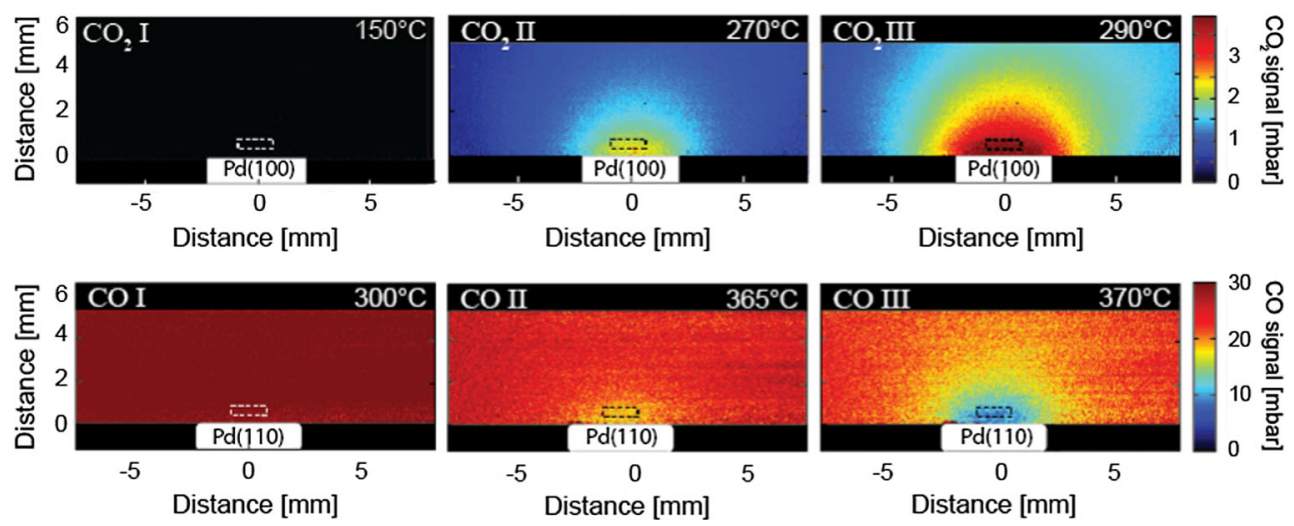

Fig. 4 PLIF images of $\mathrm{CO}_{2}$ (upper panel) and $\mathrm{CO}$ (lower panel) gasphase distributions over Pd single crystals during $\mathrm{CO}$ oxidation in a 1:1 ratio of $\mathrm{CO}$ and $\mathrm{O}_{2}$. The gas flow is in the direction from left to right in all images. The white filled rectangles represent the single crystals samples and the dashed rectangles above show the areas where the PLIF signals plotted in Fig. 5 are evaluated. The Roman numerals are correlated to time points and temperatures in Fig. 5
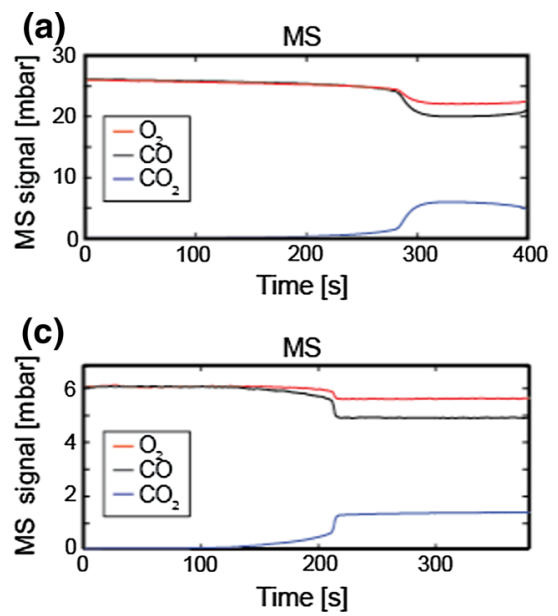

Fig. 5 Comparison of the MS and PLIF signals, a MS signal detected during CO oxidation over $\mathrm{Pd}(110)$. b Corresponding CO PLIF trend extracted $0.5 \mathrm{~mm}$ from surface and sample temperature. $\mathbf{c}$ MS signal

ignition the $\mathrm{CO}$ signal decreases simultaneously as the $\mathrm{CO}_{2}$ signal increases and both signals reach constant levels, even though the temperature is increased further. This is, as discussed above, a clear indication of an MTL reaction. In this regime the MS CO partial pressure detected at the outlet of the chamber has decreased by approximately $25 \%$. This can be compared to the CO PLIF signal plotted in Fig. 5b, extracted $0.5 \mathrm{~mm}$ from the surface (the dashed rectangle in the images in Fig. 4 shows the area where the signal is extracted) where the $\mathrm{CO}$ signal decreases by approximately $80 \%$. The Roman numerals in the plot indicate time points for the corresponding image of the gasphase distribution shown in Fig. 4. Similar divergence is also observed between the MS and $\mathrm{CO}_{2}$ PLIF signal shown in Fig. $5 \mathrm{c}$ and d, respectively. The results from the MS and PLIF can in turn be compared to the $\mathrm{C} 1 \mathrm{~s}$ peak areas
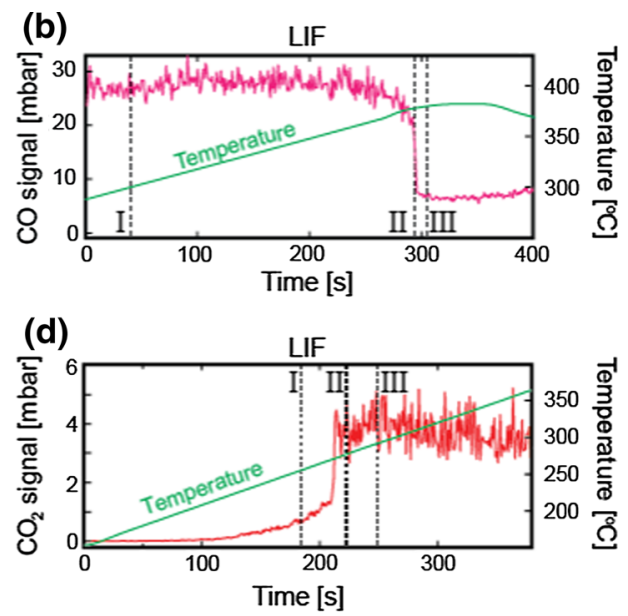

detected during $\mathrm{CO}$ oxidation over $\mathrm{Pd}(100)$. d Corresponding $\mathrm{CO}_{2}$ PLIF trend extracted $0.5 \mathrm{~mm}$ from surface and sample temperature

plotted in Fig. 3. The $\mathrm{C} 1 \mathrm{~s}$ peak areas show, just as the PLIF data, a higher ratio between the reactant and the product signal as compared to the MS signal. The reason for the different ratios detected by the different techniques can be understood by studying the PLIF images. The images reveal a completely different gas composition in the MTL regime, close to the surface where the AP-XPS and PLIF signals are extracted, which is not detected by the MS.

\section{Discussion}

The gas molecules interacting with the surface are obviously important for the surface composition, and the determination of an active site or phase of the catalyst. It is 
(a)

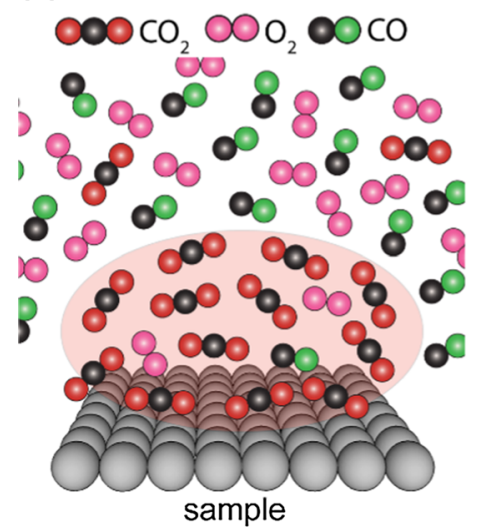

Fig. 6 Illustration of the boundary layer of $\mathrm{CO}_{2}$ during $\mathrm{CO}$ oxidation over a highly active surface. a Model showing the high $\mathrm{CO}_{2}$ and low $\mathrm{CO}$ concentration within the boundary layer. $\mathbf{b}$ Schematic view of the highly active sample surface with PLIF image showing the $\mathrm{CO}_{2}$

therefore important to gain knowledge about the gas distribution around the catalyst in order to understand to which extent relevant information can be deduced from gas-phase AP-XPS spectra. Due to the differences in the experimental set-ups, the extent and size of the gas phase distribution at MTL may be influenced by the different flow and conditions of the different set-ups, but as our results demonstrate, the main contribution to the gas-phase peaks at MTL in AP-XPS originates from the seriously CO-depleted zone, often referred to in the literature as the boundary layer. The very high conversion of $\mathrm{CO}$ that is observed in both the AP-XPS and in the PLIF signal is within this boundary layer. We do not observe any indication that the catalytic behavior at MTL is different because of the different experimental set-ups.

Both PLIF and AP-XPS show consistently a significantly different gas composition above the single crystal surfaces compared to the rest of the chamber when the MTL regime is reached, as illustrated in Fig. 6a. This behavior is observed for both the $\mathrm{Pd}(110)$ and $\mathrm{Pd}(100)$ crystals and is expected to follow for any highly active transition metal during $\mathrm{CO}$ oxidation, at least in the case of a single crystal positioned in a reactor in a similar way as in the present experiments. The concentration gradient of $\mathrm{CO}$ and $\mathrm{CO}_{2}$ within the boundary layer is dependent on the gas exchange in the chamber and the activity of the sample. The gas flow in the AP-XPS set-up is complex due to the large volume of the reactor with the only outlet being the nozzle of the analyzer. The distance between the aperture of the nozzle and the surface is about $2 \mathrm{~mm}$ resulting in a semi-flow type of reactor, and the rate of the gas exchange and the gas composition above the surface are difficult to estimate.

Comparing ratios of the $\mathrm{CO}$ and $\mathrm{CO}_{2}$ peak areas in the AP-XPS C 1s spectra, measured during the temperature ramp, as well as PLIF and MS signals, shows that AP-XPS (b)

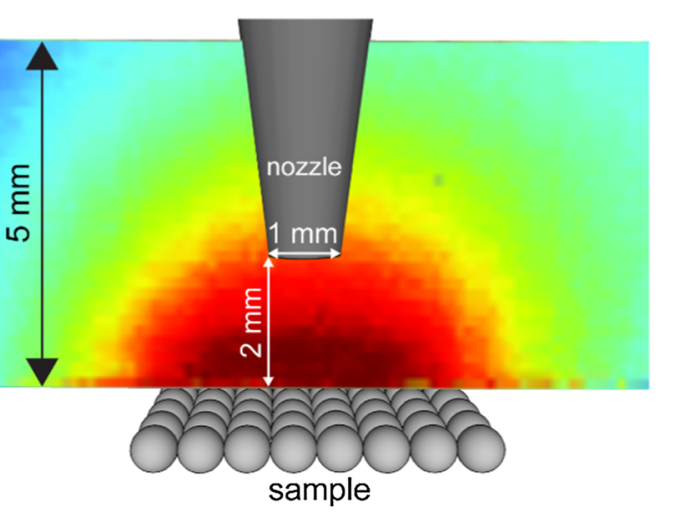

distribution above the catalyst. The AP-XPS nozzle is located at normal operating distance, which is approximately twice the diameter of the nozzle aperture. Electrons with a take-off angle of $23^{\circ}$ will reach the detector

data are in considerably better agreement with PLIF data than with MS data. The peak areas, however, differ compared with ratios of the gas-phase peak heights shown in the AP-XPS spectra (Fig. 2). The reason for the larger area of the $\mathrm{CO}$ peak is the larger splitting of the vibrational fine structure in $\mathrm{CO}$ as compared with $\mathrm{CO}_{2}$ [29, 30], which gives a broadening of the peak and generates a larger area for the $\mathrm{CO}$ peak. The stronger scattering of the electrons of the $\mathrm{CO}_{2}$ molecules might also modify the peak area, but this contribution is relatively small and will not affect the high ratio between $\mathrm{CO}$ and $\mathrm{CO}_{2}$ signals in the MTL regime. This observation indicates that most of the gas-phase molecules detected in the AP-XPS measurements originate from a region with a comparable relation between the $\mathrm{CO}$ and $\mathrm{CO}_{2}$ concentrations as inside the boundary layer imaged in the PLIF experiments, and that the aperture of the AP-XPS detector nozzle is located at a distance from the surface where the gas-phase concentration gradient has not changed significantly but reveal a similar $\mathrm{CO}$ and $\mathrm{CO}_{2}$ ratio as that close to the surface, schematically illustrated in Fig. 6b. Furthermore, the AP-XPS measurements are averaged over a volume above the surface. As a consequence, if the gas-phase distribution or the boundary layer were to be measured by AP-XPS, it is likely to appear smeared out as compared to the distribution observed by PLIF. This drastic reduction would result in a CO level just below the detection limit for AP-XPS, explaining the absence of the $\mathrm{CO}$ gas-phase peak for the highly active sample. It could be argued that the $\mathrm{CO}$ should still be detected in the AP-XPS measurements for the highest pressure, 0.13 mbar (20\% of 0.67 mbar). However, 0.13 mbar is close to the general detection limit of AP-XPS ( 0.05 mbar) [31], which is further affected by the photoelectron kinetic energy, the photoelectron cross-section, and the types of gases used in the experiments. The PLIF 
measurements, however, confirm that $\mathrm{CO}$ is still present in the gas-phase above the crystal but the concentration decreases by approximately $80 \%$ compared to the initial $\mathrm{CO}$ level. This is interpreted as the fast build-up of the boundary layer of $\mathrm{CO}_{2}$ after ignition that hinders $\mathrm{CO}$ to reach the surface which decreases the $\mathrm{CO}$ concentration close to the surface significantly in the MTL regime.

\section{Conclusions}

The PLIF images of $\mathrm{CO}$ and $\mathrm{CO}_{2}$ display a boundary layer with a spherical shape around the surface when the MTL is reached during $\mathrm{CO}$ oxidation. This boundary layer has a significantly different gas composition than that measured at the chamber gas inlet or outlet, with a $\mathrm{CO}$ concentration below the detection limit of the AP-XPS. By studying the gas-phase peak areas extracted from the C 1s AP-XPS spectra and compare with the PLIF and MS results, we confirm that the ratio of $\mathrm{CO}$ and $\mathrm{CO}_{2}$ concentrations detected by AP-XPS is comparable with the gas ratio inside the boundary layer. The results indicate that the gas-phase peaks in the AP-XPS spectra represent the gas phase interacting with the surface, and that the aperture of the nozzle is located at a distance from the surface where the $\mathrm{CO}$ and $\mathrm{CO}_{2}$ concentrations are still similar as within the boundary layer. AP-XPS is therefore one of few techniques able to probe the gas phase just above the catalyst surface. This makes AP-XPS suitable for in situ catalysis studies where the spectra can provide information about the gas phase molecules relevant for the surface structure determination of a highly active catalyst.

Altogether, the presence of a boundary layer in the highly active phase of the catalyst implies that in situ studies are important when $\mathrm{CO}$ oxidation is investigated in order to achieve a representative picture of the surface structure and the gas molecules interacting with the surface.

Acknowledgments The authors gratefully acknowledge financial support from the Knut and Alice Wallenberg Foundation and the Swedish Research Council.

Open Access This article is distributed under the terms of the Creative Commons Attribution 4.0 International License (http://creative commons.org/licenses/by/4.0/), which permits unrestricted use, distribution, and reproduction in any medium, provided you give appropriate credit to the original author(s) and the source, provide a link to the Creative Commons license, and indicate if changes were made.

\section{References}

1. Freund HJ, Meijer G, Scheffler M, Schlogl R, Wolf M (2011) CO oxidation as a prototypical reaction for heterogeneous processes. Angew Chem Int Edit 50:10064-10094
2. Ertl G, Knozinger H, Weitkamp J (2008) Handbook of heterogeneous catalysis, 2nd edn. Wiley-VCH, Weinheim

3. Gustafson J, Shipilin M, Zhang C, Stierle A, Hejral U, Ruett U, Gutowski O, Carlsson PA, Skoglundh M, Lundgren E (2014) High-energy surface X-ray diffraction for fast surface structure determination. Science 343:758-761

4. Gao F, Wang Y, Cai Y, Goodman DW (2009) CO oxidation on Ptgroup metals from ultrahigh vacuum to near atmospheric pressures. 2. Palladium and platinum. J Phys Chem C 113:174-181

5. Hendriksen BLM, Bobaru SC, Frenken JWM (2004) Oscillatory CO oxidation on Pd(100) studied with in situ scanning tunneling microscopy. Surf Sci 552:229-242

6. Grass ME, Zhang YW, Butcher DR, Park JY, Li YM, Bluhm H, Bratlie KM, Zhang TF, Somorjai GA (2008) A reactive oxide overlayer on rhodium nanoparticles during $\mathrm{CO}$ oxidation and its size dependence studied by in situ ambient-pressure X-ray photoelectron spectroscopy. Angew Chem Int Ed 47:8893-8896

7. Bluhm H, Havecker M, Knop-Gericke A, Kiskinova M, Schlogl R, Salmeron M (2007) In situ X-ray photoelectron spectroscopy studies of gas-solid interfaces at near-ambient conditions. MRS Bull 32:1022-1030

8. Matera S, Reuter K (2009) First-principles approach to heat and mass transfer effects in model catalyst studies. Catal Lett 133:156-159

9. Duprat F (2002) Light-off curve of catalytic reaction and kinetics. Chem Eng Sci 57:901-911

10. Grass ME, Karlsson PG, Aksoy F, Lundqvist M, Wannberg B, Mun BS, Hussain Z, Liu Z (2010) New ambient pressure photoemission endstation at advanced light source beamline 9.3.2. Rev Sci Instrum 81(5):053106

11. Bluhm H (2010) Photoelectron spectroscopy of surfaces under humid conditions. J Electron Spectrosc 177:71-84

12. Siegbahn K (1969) ESCA applied to free molecules. NorthHolland Publishing, Amsterdam

13. Blomberg S, Hoffmann MJ, Gustafson J, Martin NM, Fernandes VR, Borg A, Liu Z, Chang R, Matera S, Reuter K, Lundgren E (2013) In situ X-ray photoelectron spectroscopy of model catalysts: at the edge of the gap. Phys Rev Lett 110:117601

14. Toyoshima R, Yoshida M, Monya Y, Suzuki K, Mun BS, Amemiya K, Mase K, Kondoh H (2012) Active surface oxygen for catalytic $\mathrm{CO}$ oxidation on $\mathrm{Pd}(100)$ proceeding under near ambient pressure conditions. J Phys Chem Lett 3:3182-3187

15. Toyoshima R, Yoshida M, Monya Y, Suzuki K, Amemiya K, Mase K, Mun BS, Kondoh H (2013) In situ photoemission observation of catalytic $\mathrm{CO}$ oxidation reaction on $\mathrm{Pd}(110)$ under near-ambient pressure conditions: evidence for the langmuirhinshelwood mechanism. J Phys Chem C 117:20617-20624

16. Toyoshima R, Yoshida M, Monya Y, Kousa Y, Suzuki K, Abe H, Mun BS, Mase K, Amemiya K, Kondoh H (2012) In situ ambient pressure XPS study of $\mathrm{CO}$ oxidation reaction on $\mathrm{Pd}(111)$ surfaces. J Phys Chem C 116:18691-18697

17. Zellner A, Suntz R, Deutschmann O (2015) Two-dimensional spatial resolution of concentration profiles in catalytic reactors by planar laser-induced fluorescence: NO reduction over diesel oxidation catalysts. Angew Chem Int Ed 54:2653-2655

18. Appel C, Mantzaras J, Schaeren R, Bombach R, Kaeppeli B, Inauen A (2002) An experimental and numerical investigation of turbulent catalytically stabilized channel flow combustion of hydrogen/air mixtures over platinum. P Combust Inst 29: 1031-1038

19. Blomberg S, Brackmann C, Gustafson J, Aldén M, Lundgren E, Zetterberg J (2015) Real-time gas-phase imaging over a Pd(110) catalyst during $\mathrm{CO}$ oxidation by means of planar laser-induced fluorescence. ACS Catal 5(4):2028-2034

20. Zetterberg J, Blomberg S, Gustafson J, Evertsson J, Zhou J, Adams CE, Carlsson PA, Aldén M, Lundgren E (2015) Spatially 
and temporally resolved gas distributions around heterogeneous catalysts using infrared planar laser-induced fluorescence. Nat Commun 6:7076

21. Chang R, Hong YP, Axnanda S, Mao BH, Jabeen N, Wang SD, Tai RZ, Liu Z (2012) In-situ photoelectron spectroscopy with online activity measurement for catalysis research. Curr Appl Phys 12:1292-1296

22. Zetterberg J, Blomberg S, Gustafson J, Sun ZW, Li ZS, Lundgren $\mathrm{E}$, Alden $\mathrm{M}$ (2012) An in situ set up for the detection of $\mathrm{CO}_{2}$ from catalytic $\mathrm{CO}$ oxidation by using planar laser-induced fluorescence. Rev Sci Instrum 83:053104

23. Doniach S, Šunjić M (1970) Many-electron singularity in X-ray photoemission and X-ray line spectra from metals. J Phys Part C Solid 3:285-291

24. Eckbreth AC (1988) Laser diagnostics for combustion temperature and species. Energy and engineering science series, vol 7. Abacus Press, Tunbridge Wells, Kent; Cambridge, Mass

25. Andersen JN, Qvarford M, Nyholm R, Sorensen SL, Wigren C (1991) Surface core-level shifts as a probe of the local overlayer structure-Co on Pd(100). Phys Rev Lett 67:2822-2825

26. Siegbahn H (1985) Electron-spectroscopy for chemical-analysis of liquids and solutions. J Phys Chem 89:897-909
27. Axnanda S, Scheele M, Crumlin E, Mao BH, Chang R, Rani S, Faiz M, Wang SD, Alivisatos AP, Liu Z (2013) Direct work function measurement by gas phase photoelectron spectroscopy and its application on $\mathrm{PbS}$ nanoparticles. Nano Lett 13: 6176-6182

28. Shirley DA, Kobrin PH, Truesdale CM, Lindle DW, Ferrett TA, Heimann PA, Becker U, Kerkhoff HG, Southworth SH (1984). Gas-phase photoemission with soft X-Rays: Cross sections and angulardistributions. Proc. SPIE 0447:150-156

29. Neeb M, Kempgens B, Kivimaki A, Koppe HM, Maier K, Hergenhahn U, Piancastelli MN, Rudel A, Bradshaw AM (1998) Vibrational fine structure on the core level photoelectron lines of small polyatomic molecules. J Electron Spectrosc 88:19-27

30. Kempgens B, Maier K, Kivimaki A, Koppe HM, Neeb M (1997) Vibrational excitation in $\mathrm{C}$ 1s and $\mathrm{O}$ 1s photoionization of $\mathrm{CO}$. J Phys B 30:L741-L747

31. Crumlin EJ, Bluhm H, Liu Z (2013) In situ investigation of electrochemical devices using ambient pressure photoelectron spectroscopy. J Electron Spectrosc 190:84-92 